\title{
Professionalism and performance issues during neurosurgical training and job satisfaction after training: a single training center 50-year experience
}

\author{
William C. Newman, MD, Yue-Fang Chang, PhD, and L. Dade Lunsford, MD \\ Department of Neurological Surgery, University of Pittsburgh Medical Center, Pittsburgh, Pennsylvania
}

OBJECTIVE Neurosurgery is often self-selecting. Concern has been raised that residents in the millennial era (born between 1982 and 2004) may have more serious professionalism and performance issues (PPIs) during training compared to prior trainees. Serious PPIs were defined as concerns that led to specific resident disciplinary actions ranging from initial warnings to termination. In order to evaluate this concern, the authors retrospectively reviewed a 50 -year experience at a single training center. They then prospectively surveyed living graduates of the program to assess variations in practice patterns and job satisfaction over 5 decades.

METHODS The PPIs of 141 residents admitted for training at the University of Pittsburgh (subsequently UPMC) Department of Neurological Surgery were reviewed by decade starting in 1971 when the first department chair was appointed. The review was conducted by the senior author, who served from 1975 to 1980 as a resident, as a faculty member since 1980, and as the resident director since 1986. A review of resident PPIs between 1971 and 1974 was performed in consultation with a senior faculty member active at that time. During the last decade, electronic reporting of PPIs was performed by entry into an electronic reporting system. In order to further evaluate whether the frequency of PPIs affected subsequent job satisfaction and practice patterns after completion of training, the authors surveyed living graduates.

RESULTS There was no statistically significant difference by decade in serious PPIs. Although millennial residents had no significant increase in the reporting of serious PPIs, the increased use of electronic event reporting over the most recent 2 decades coincided with a trend of increased reporting of all levels of suspected PPIs $(p<0.05)$. Residents surveyed after completion of training showed no difference by decade in types of practice or satisfaction-based metrics $(p>0.05)$ but reported increasing concerns related to the impact of their profession on their own lifestyle as well as their family's.

CONCLUSIONS There was no statistically significant difference in the incidence of serious PPIs over 5 decades of training neurosurgery residents at the authors' institution. During the millennial era, serious PPIs have not been increasing. However, reporting of all levels of PPIs is increasing coincident with the ease of electronic reporting. There was remarkably little variance in satisfaction metrics or type of practice over the 5 decades studied.

https://thejns.org/doi/abs/10.3171/2018.3.JNS172347

KEYWORDS neurosurgical training; neurosurgical residency; professionalism

$\mathrm{W}$ HILE many neurosurgical training programs, including our own, have reported on their origin and evolution, $, 4,6,7,10,12$ our goal was to evaluate whether the characteristics of neurosurgical trainees at our center have evolved over time. This question has been raised because of concerns that millennial residents (those born between 1982 and 2004) have an increased incidence of serious professionalism or performance issues (PPIs) compared to residents selected for training in prior years. Serious performance issues included unremediable knowledge deficits or inadequate technical skill acquisition. Examples of serious professionalism issues included unacceptable faculty interactions, anger management difficulties, cultural sensitivity issues, inappropriate gender or sexual interactions, poor fit for the program, sociopathic behaviors, arrests, and substance abuse issues. Serious issues resulted in one or more actions: oral and written review and citation in the resident's record, leave of absence, remediation, probation, last-chance agreements, or dismissal. 
TABLE 1. University of Pittsburgh graduate demographics

\begin{tabular}{lcccc}
\hline Decade & $\begin{array}{c}\text { No. of } \\
\text { Residents }\end{array}$ & $\begin{array}{c}\text { No. to } \\
\text { Graduate }\end{array}$ & $\begin{array}{c}\text { Male } \\
\text { Gender }\end{array}$ & $\begin{array}{c}\text { Dual } \\
\text { Degree }\end{array}$ \\
\hline $1971-1980$ & 26 & 21 & $26(100 \%)$ & 1 \\
\hline $1981-1990$ & 22 & 18 & $22(100 \%)$ & 2 \\
\hline $1991-2000$ & 26 & 25 & $26(100 \%)$ & 5 \\
\hline $2001-2010$ & 31 & 29 & $28(90.3 \%)$ & 10 \\
\hline $2011-2017$ & 23 & 19 & $21(91 \%)$ & 2 \\
\hline Total & 128 & 112 & $123(96 \%)$ & 20 \\
\hline
\end{tabular}

Given the concerns regarding the potentially changing nature of future neurosurgeons, we decided to perform a 5-decade review of trainees admitted to our program in order to assess whether resident characteristics have changed over time. We reviewed the training records of all residents admitted to the program. We noted any serious PPI that led to specific interventions that ranged from an oral and written reprimand to termination. We then conducted a brief survey of successful graduates to determine whether job satisfaction and career choice and focus varied over these same 5 decades.

\section{Methods}

The records of all 141 Department of Neurological Surgery residents who matriculated at the University of Pittsburgh since 1971 were reviewed by the senior author (L.D.L.), the current residency program director, who began training at the University of Pittsburgh in 1975. As of this writing, he has practiced there for 37 years after completing his training, serving as a faculty member since 1980 and as resident director since 1986. To evaluate the years 1971-1975, the senior author conducted a compre- hensive review of PPIs in residents who were then receiving training by a senior clinical professor of neurosurgery at the University of Pittsburgh. Their combined tenure at the University of Pittsburgh spans the entirety of the years surveyed (1971-2017 for current graduates and up to 2020 for expected graduates). These records were reviewed to assess all reports of serious PPIs during training, including written and electronic (i.e., electronic mail or reporting within the electronic medical record [EMR] system).

Additionally, a brief 10-question survey was distributed to living graduates from the department. This survey included questions relating to their type of practice and employment, their overall job satisfaction, the number of cities in which they have practiced, the impact of their career on their family life, the focus of their practice, and the volume of malpractice litigation they have been involved in.

The results of the historical review and the brief questionnaire were then stratified by decade of graduation in order to create comparison groups over time. Chi-square tests and Fisher's exact tests were used to determine statistical significance of differences between decades with $p$ $<0.05$ considered significant.

\section{Results}

Of the 141 residents who began training after July 1, 1971, 112 had graduated as of June 30, 2017 (Table 1). During these 46 years, 16 residents left the program. Thirteen residents are anticipated to graduate between 2017 and 2020, concluding the 50-year analysis.

\section{Professionalism and Performance Issues}

With respect to professionalism and performance issues (PPIs), all 141 residents who began training with a plan to complete by 2020 were included (Fig. 1). Over the decades, we found no statistically significant difference in

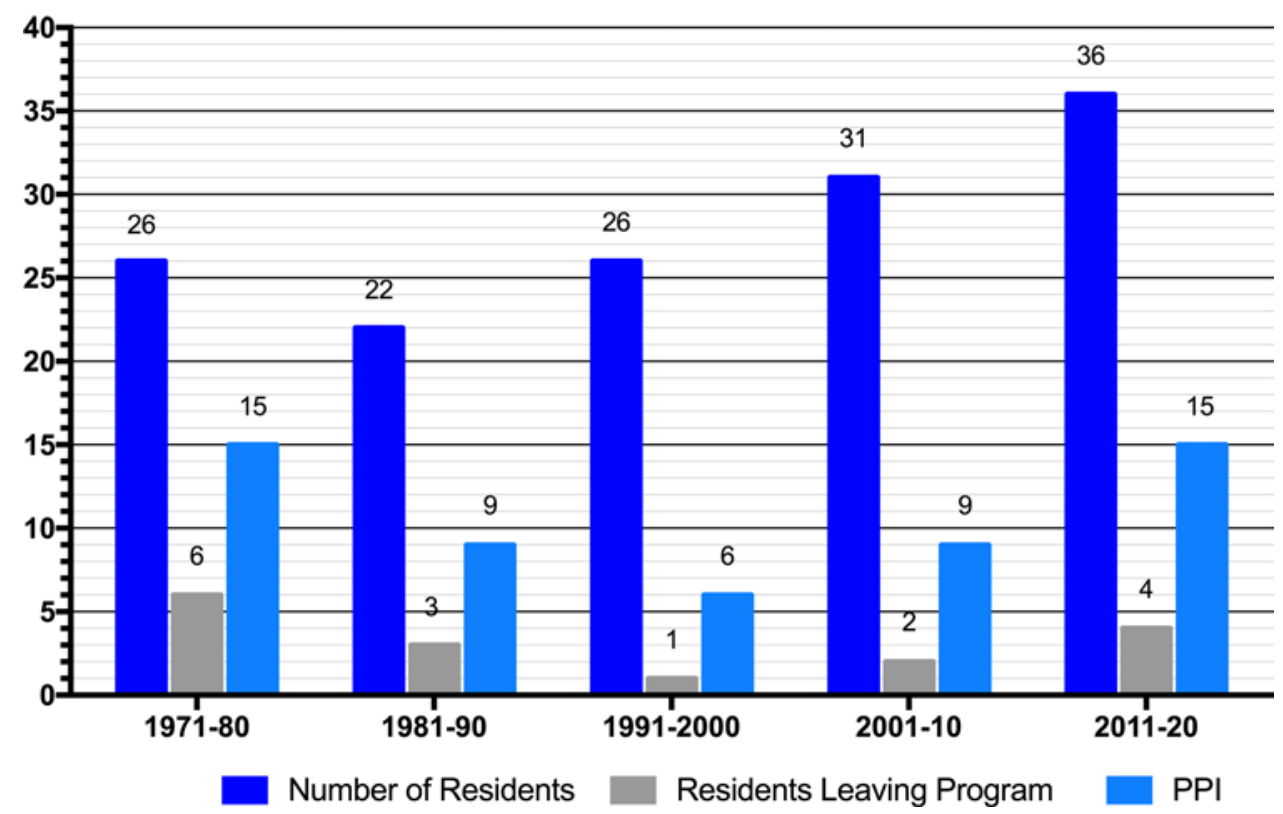

FIG. 1. Number of resident PPIs and program-exiting events by decade. Includes projections regarding future neurosurgical graduates from 2017 to 2020. 
TABLE 2. Breakdown of performance and behavior issues

\begin{tabular}{lc}
\hline \multicolumn{1}{c}{ Issue } & No. of Residents (\% of total) \\
\hline Performance issues & \\
\hline Knowledge & $21(15)$ \\
\hline Poor technical skill & $1(0.7)$ \\
\hline Behavioral issues & $1(0.7)$ \\
\hline Incompatible with chairman & $13(9)$ \\
\hline Anger management & $3(2)$ \\
\hline Cultural & $1(0.7)$ \\
\hline Cultural and sexual & $1(0.7)$ \\
\hline Sexual & $10(7)$ \\
\hline Fit for program & $1(0.7)$ \\
\hline Sociopathic behaviors & $2(1.4)$ \\
\hline Substance abuse &
\end{tabular}

the number of serious PPIs $(p=0.815)$. Overall, $38 \%$ of residents had at least 1 PPI that required corrective action. During the last decade, we observed a gradual decreasing trend in professionalism issues, but this observation failed to reach statistical significance $(p=0.065)$. There was no difference over the decades with respect to residents leaving voluntarily or being terminated from the program ( $\mathrm{p}$ $=0.245$ ). Sixteen residents (11\%) eventually left training, most often within the first 2 years. Eleven of these 16 residents $(69 \%)$ changed specialties to another field, while 5 (31\%) changed to a different neurosurgical program and completed training.

In total, 54 residents $(38 \%)$ had at least 1 PPI (Table 2). Thirty-six (67\%) responded to corrective action and completed training at our institution. Twenty-two residents had significant performance issues; 21 had deficiencies in knowledge acquisition and 1 trainee failed to gain satisfactory technical skills. Professionalism issues resulting in disciplinary action were recorded for 32 trainees, including 13 residents with repeated anger management issues, 3 international background trainees with cultural adaptation deficiencies, 2 residents who required intervention and residential treatment for substance abuse, 2 residents who required discipline for inappropriate sexual and gender behavior, and 2 residents who were arrested during their training. One resident was arrested for driving the wrong way down a 1-way street while under the influence; the case was resolved with an accelerated rehabilitation agreement. One resident became the defendant in a case of suspected maritime boat piracy during a flood of the Pittsburgh rivers. This case was won by the defendant resident. One resident was terminated because of suspected sociopathic behavior tendencies after less than 1 year.

\section{Recent Impact of Electronic Reporting of Suspected PPIs}

While there was not a statistically significant increase over time in the number of serious PPIs requiring intervention, we did detect an increased rate of electronic incident reporting over time ( $\mathrm{p}<0.05)$ (Fig. 2). Electronic reporting via the hospital Risk Master system is available to all medical, nursing, and technical staff at our hospital. Increasing access to electronic reporting began in 2001, and since that time, we noted a significant increase in the number of reported incidents of suspected PPIs. These reports are individually investigated by the resident director, but upon review none were deemed to rise to the level of a serious PPI that required corrective actions. Prior to 2001, all PPIs were generated through direct oral or written documentation with notations of adjudication and management left in the individual resident portfolio. After 2001, incidents could be reported through oral or written documentation, electronic mail, or the use of Risk Master in the EMR of individual patients. Since the creation of this elec-

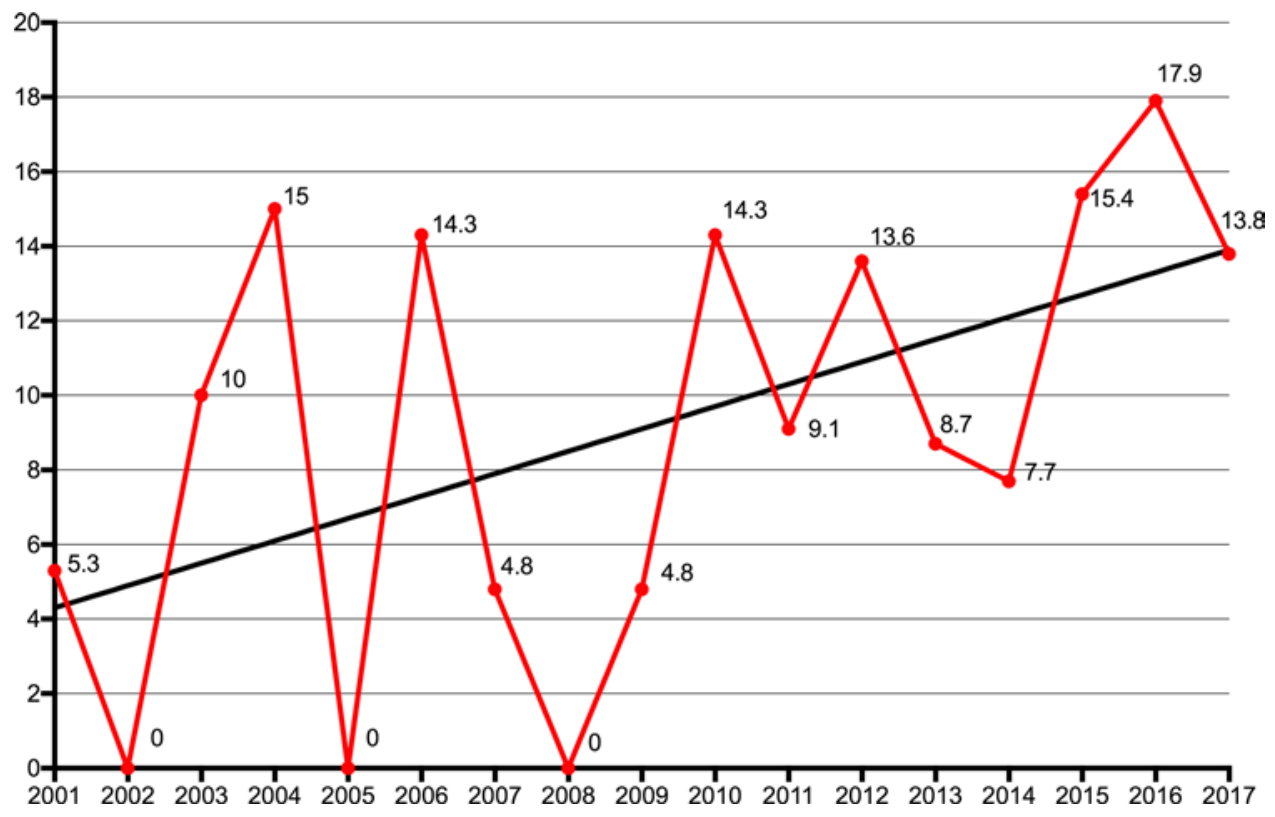

FIG. 2. Percentage of residents with an incident report over time from 2001 to 2017. Black line represents the trend over time. 
tronic method to lodge concerns related to resident performance, an increase in these reported concerns has been documented (Fig. 2). Each concern has been evaluated by the current resident director and adjudicated as to whether it constituted a serious PPI. Such PPIs required a face-toface meeting, documentation in the resident portfolio, an action plan for improvement, or in certain cases referral to a resident assistance program. Repeated PPIs led to remediation, probation, creation of a last-chance agreement, or termination. Drug-related behavior (2 residents) led to referral for inpatient rehabilitation and eventual successful performance.

\section{Graduated Resident Survey Results}

Of the 112 eligible graduates, 5 were deceased, 8 had no contact information, and 3 graduated in 2017, yielding 96 graduates eligible to complete the survey. Seventy-seven of $96(80.2 \%)$ eligible graduates completed our 10 -question survey. Seventeen $(22 \%)$ were graduates from 1989 or earlier, 18 (23.4\%) graduated between 1990 and 1999, 24 (31.2\%) graduated between 2000 and 2009, and $18(23.4 \%)$ graduated between 2010 and 2016. These date ranges were chosen to create roughly equivalent numbers of graduates within the cohorts for comparison across the years. As of 2017, 7 women (5\%) had been admitted for training, with 2 currently in training and 4 having successfully completed training at our center. One female resident transferred to another training program and completed training there. The first female trainee was admitted in 1996 and the last two in 2017. Therefore, during this period of almost 50 years, the vast majority of trainees (95\%) were male. Although most trainees were admitted after obtaining a single professional degree, their medical doctorate, we found a significant increase in dual-degree residents over time $(\mathrm{p}<0.05)$ (Table 1$)$.

Our brief 10-question survey asked graduated residents about various aspects of their current practice and general satisfaction with neurosurgery as a career choice. We noted a few differences over these 5 decades. More recent graduates were more likely to be currently practicing ( $\mathrm{p}$ $<0.05$ ) and have an additional degree gained before or during residency $(\mathrm{p}=0.01)$. We inquired whether graduates were more likely to shift their site of practice as years went by. When controlling for the number of years out of practice, graduates were not more likely by decade to have practiced in more cities over these 5 decades $(\mathrm{p}=$ 0.82 ). We also inquired about the volume of malpractice litigation but found no significant difference over time in the risk of malpractice litigation $(\mathrm{p}=0.10)$. There was no statistically significant difference over the decades with respect to the type of employment (e.g., private practice, multispecialty group practice, health system, or university-affiliated practice) $(\mathrm{p}=0.36)$. Of the 46 graduates who identified themselves as having an academic appointment, those from earlier decades were more likely to have achieved higher-level academic positions $(\mathrm{p}<0.05)$. Across the decades, there was no significant difference in the focus of the graduates' practice (e.g., predominantly cranial, mostly spinal, mixed, or hospital administrative in nature) $(\mathrm{p}=0.33)$ (Table 3$)$.

To assess additional quality-of-life issues we asked graduates to rate their career satisfaction, the impact of their career on their immediate family, and whether, in retrospect, they would choose to pursue neurosurgery again. Concerning career satisfaction, there was no significant difference in satisfaction by graduation decade $(\mathrm{p}=$ 0.93 ), with all respondents rating their satisfaction as "satisfied" or "very satisfied." When asked about the impact of their career on their family, there was no statistically significant difference over the decades $(p=0.354)$, although a higher percentage of those graduating between 2000 and 2009 reported a negative impact on their family than their counterparts who graduated between 1977 and 1989 ( $16.7 \%$ negative/moderately negative compared to $11.8 \%$, respectively). For the same question, the most recent group of graduates answered their questionnaire with satisfaction percentages that were identical to those of their predecessors from 1977 to 1989 (Table 3). Of female graduate respondents $(n=4)$ describing the effect of their career on their family, two rated it as "negative." Three respondents stated they would choose to pursue neurosurgical training again. Two respondents were "very satisfied" with their career, while two were moderately satisfied.

Of note, the survey did not require graduates to answer every question, and 3 respondents elected not to answer selected questions. Therefore, the values for specific categories and decades in Table 3 will not add up to the total number of respondents given in the column heads.

\section{Discussion}

\section{Have Professionalism and Performance Issues Increased Over the Last 50 Years?}

Neurosurgery has been described as a self-selected personal lifestyle choice beginning with the 7 years now required for training (in fact, neurosurgery is the only current Accreditation Council on Graduate Medical Education [ACGME] training program that is 7 years). There have been numerous articles written describing millennial physicians, detailing their vices and virtues, and attempting to predict their impact on the future of medicine. ${ }^{5,8,11,13,14}$ Most of what has been studied about millennials relates to how to educate and assess a new generation of physicians who relate better to technology and the efficiency that it brings. ${ }^{3,9,11}$ Over the last 2 decades, we also became subtly concerned that trainees who self-select neurosurgery may not be as focused, committed, or prepared for the rigors of the profession. For example, millennial physicians have been characterized as less likely to go into solo practice, ${ }^{13}$ more likely to prioritize family life and work-life balance,,$^{11,13,14}$ and more likely to have secondary degrees with plans to work both as a physician and in some extramedical capacity. ${ }^{14}$ Additionally, some have suggested that millennials value control over schedule, adequacy of leisure time, and income commensurate to their workload more than their predecessors. ${ }^{5}$ Anecdotally, it has even been suggested that the newer generation of physicians differs from their predecessors with respect to their interpersonal behaviors. ${ }^{8}$

In order to add data to these arguments about the potentially changing landscape of neurosurgical trainees, we collected information on our selected residents with 
TABLE 3. Neurosurgical practice and lifestyle questionnaire responses

\begin{tabular}{|c|c|c|c|c|c|}
\hline & $1977-1989(n=17)$ & $1990-1999(n=18)$ & $2000-2009(n=24)$ & $2010-2016(n=18)$ & $p$ Value \\
\hline Currently practicing & & & & & 0.034 \\
\hline Full time & $11(65)$ & $15(83)$ & $23(96)$ & $18(100)$ & \\
\hline Part time & $2(12)$ & $2(11)$ & $0(0)$ & $0(0)$ & \\
\hline Retired & $3(18)$ & $1(6)$ & $1(4)$ & $0(0)$ & \\
\hline Other & $1(6)$ & $0(0)$ & $0(0)$ & $0(0)$ & \\
\hline Cities practiced in & & & & & $0.821^{*}$ \\
\hline 1 & $7(41)$ & $9(50)$ & $13(54)$ & $15(83)$ & \\
\hline 2 & $3(18)$ & $6(33)$ & $7(29)$ & $1(6)$ & \\
\hline $3+$ & $7(42)$ & $3(17)$ & $4(17)$ & $2(11)$ & \\
\hline Satisfied with your career & & & & & 0.929 \\
\hline Very satisfied & $11(65)$ & $12(71)$ & $14(58)$ & $13(72)$ & \\
\hline Moderately satisfied & $4(24)$ & $3(18)$ & $8(33)$ & $4(22)$ & \\
\hline Satisfied & $2(12)$ & $2(12)$ & $2(8)$ & $1(6)$ & \\
\hline Moderately dissatisfied & $0(0)$ & $0(0)$ & $0(0)$ & $0(0)$ & \\
\hline Very dissatisfied & $0(0)$ & $0(0)$ & $0(0)$ & $0(0)$ & \\
\hline Impact of career on family & & & & & 0.354 \\
\hline Very positive & $4(24)$ & $9(53)$ & $5(21)$ & $4(24)$ & \\
\hline Moderately positive & $5(29)$ & $1(6)$ & $3(13)$ & $5(29)$ & \\
\hline Positive & $6(35)$ & $4(24)$ & $12(50)$ & $6(35)$ & \\
\hline Negative or moderately negative & $2(12)$ & $3(18)$ & $4(17)$ & $2(12)$ & \\
\hline Any lawsuits & & & & & 0.003 \\
\hline No & $0(0)$ & $3(17)$ & $4(17)$ & $9(50)$ & \\
\hline Yes & $17(100)$ & $15(83)$ & $20(83)$ & $9(50)$ & \\
\hline Number of lawsuits & & & & & $0.101^{*}$ \\
\hline 0 & $0(0)$ & $3(17)$ & $4(17)$ & $9(50)$ & \\
\hline 1 & $5(29)$ & $5(28)$ & $10(42)$ & $6(33)$ & \\
\hline 2 & $2(12)$ & $1(6)$ & $3(13)$ & $2(11)$ & \\
\hline $3+$ & $10(59)$ & $9(50)$ & $7(29)$ & $1(6)$ & \\
\hline Practice focus & & & & & 0.333 \\
\hline Mostly cranial & $8(47)$ & $9(50)$ & $10(42)$ & $13(76)$ & \\
\hline Mostly spinal & $4(24)$ & $2(11)$ & $6(25)$ & $2(12)$ & \\
\hline Mixed & $2(12)$ & $5(28)$ & $7(29)$ & $2(12)$ & \\
\hline Hospital admin or other & $3(18)$ & $2(11)$ & $1(4)$ & $0(0)$ & \\
\hline Would you choose neurosurgery again? & & & & & 0.198 \\
\hline Yes & $12(71)$ & $13(81)$ & $20(83)$ & $16(94)$ & \\
\hline No & $4(24)$ & $3(19)$ & $4(17)$ & $0(0)$ & \\
\hline Other & $1(6)$ & $0(0)$ & $0(0)$ & $1(6)$ & \\
\hline
\end{tabular}

Admin = administration.

Data are numbers of graduates or current residents (\% of that decade's graduates). All percentages were rounded to the nearest whole number. Because respondents did not always answer all questions in the survey, the totals for specific categories may differ from the total number of respondents.

${ }^{*} p$ value when controlling for number of years out of practice.

respect to professionalism and performance during training. Comparing across 5 decades, serious PPIs as well as the rate of residents leaving before completion of training were not significantly different ( $p>0.05$ for all). However, we did find that the implementation of electronic reporting methods resulted in a higher number of reported PPIs over the last decade $(p<0.05)$. Many such reports were deemed minor and not serious PPIs. Simple face-to-face discussion and analysis of the issue was sufficient to in- struct the trainee on better methods to "stay off the radar screen." We do not believe that overall resident serious PPIs have increased over time. Instead, we suspect that the goal of providing professionalism instruction to trainees has been amplified by the ease of online reporting in our EMR. Healthcare providers are encouraged to use Risk Master to document concerns and thereby create an electronic trail that requires a response by departmental leadership. We found that since the advent of the EMR 
in 2001, there has been a statistically significant rise in the number of reported events $(p<0.05)$ despite the $a b-$ sence of a concomitant increase in the number of serious PPIs requiring interventions that ranged from remediation to dismissal. Enhanced scrutiny has been mandated in response to meeting professionalism goals created by the ACGME. All such complaints require an investigation and written response from the program director. We suspect that the quality of the residents is not changing. Instead, current guidelines and declining tolerance of any perceived professionalism or performance infraction have led to the reporting of even minor concerns.

\section{How Are Neurosurgery Graduates Faring?}

Overall, we found that our more recent graduates were not significantly different than their predecessors. When we controlled for the number of years out of residency, we found that no group was more likely than another to relocate more frequently or to have more lawsuits ( $p>0.05$ for all). With respect to career satisfaction, there was no significant difference between the decades $(p=0.93)$, with the most recent graduates having career satisfaction scores that are very similar to the scores of their oldest predecessors.

While personal career satisfaction was stable over the years, we noted a concerning trend regarding the perceived impact of the physician's career on his or her family. Although we found no statistically significant difference between the decade groups $(\mathrm{p}=0.354)$, our oldest graduates and our most recent graduates share a similar view of the impact of their job on their families. Only $24 \%$ of the oldest and the most recent graduates stated the impact was very positive compared to 53\% of those graduating between 1990 and 1999; 64\% of the oldest and most recent graduates viewed their career's impact on their family as moderately positive or positive as compared to $30 \%$ of those from 1990 to 1999 (Table 3). Additionally, 2 of the 4 female graduates viewed the impact of their career on their family life as negative, while 3 of the 4 stated that they would still choose neurosurgery again for a career. Across all decades, there was a consistently low number of graduates who rated the impact of their career on their family as negative or moderately negative.

What is surprising is that the most recent graduates are starting off with a baseline sentiment that mirrors that of those who have been in practice for two or more decades longer. This raises the question as to how their satisfaction will change over time and if they will become more dissatisfied as their careers progress or if their early lower level of satisfaction is a reflection of the difficulties of the life of an early-career neurosurgeon. If so, these negative perceptions may resolve over time. It is also interesting that the perceived impact on family life is not reflected in the physician's personal job satisfaction, as $72 \%$ of the youngest graduates are very satisfied with their career. This raises the question as to what aspect of their work is keeping them satisfied but negatively impacting their family. It is possible that while physicians continue to find their jobs fulfilling, long hours, electronic documentation requirements, and call responsibilities limit the time that they are able to spend on family activities outside of the workplace. ${ }^{2}$ This, in turn, may lead to absenteeism, family conflict, and a negative impact on family life.

While our study has not found a significant difference between the more recently trained residents and those from prior decades, it has raised interesting questions about whether the recent emphasis on professionalism in the current training milieu has evolved. Electronic reporting may make even minor behavior or performance concerns too easy to express as we did not find that serious resident performance or behavioral issues have increased even though the number of reported events has. Our study has also raised questions regarding future physician happiness and the perceived impact of their career on their family. In this setting, it will be interesting to conduct follow-up surveys in the upcoming decades and track the progression of these responses over time. Also, as time passes and more millennial physicians graduate, such a study would give us a better look at potential changes that may be associated with the millennial physician. We did not find that the core characteristics of our neurosurgical trainees changed over time.

\section{Study Limitations}

While we did not find significant changes in our trainees over time, several limitations of our study must also be acknowledged. First, while we achieved an $81.3 \%$ survey response rate, there may still exist a self-selection bias with respect to those who chose not to respond to our survey. Such a bias may confound our satisfaction results. Second, we did not survey residents regarding the impact of duty hour restrictions on their perceived satisfaction. However, since these restrictions were imposed formally in 2011, this is a factor that will be relevant to future surveys and did not impact the vast majority of graduates that we surveyed. Third, our study is retrospective in nature and subject to the biases of underreporting and differences in the thoroughness of documentation. However, during the period studied, there were only 2 program directors tasked with handling all reported issues. Last, our paper only represents a single institutional experience and thus is a potentially biased personal selection of those who have chosen to matriculate at the University of Pittsburgh and its current medical center, UPMC. In order to overcome this bias, multiple centers may benefit from performing similar retrospective reviews and pooling their data to see if there are regional or national trends or differences in the evolution of neurosurgical trainees.

\section{Conclusions}

Over the last 50 years of training neurosurgery residents at this program, we did not find a statistically significant change in serious PPIs. We did find an association between the ease of current electronic methods to report perceived deficiencies in resident PPIs (including minor concerns) and an increasing number of reported events. From our survey of more than $80 \%$ of our graduates over these 50 years, we did detect a potential trend toward decline in the subsequent job satisfaction of graduating residents, though this did not reach significance. It may take another 10 years to determine if a career such as neurosurgery fits attributes 
ascribed to millennial physicians. Perhaps those who selfselect neurosurgical training are less affected by reported millennial lifestyle goals. Additional retrospective reviews and surveys may help us to understand the changing training landscape and millennials' role within it. While we suspect that those entering neurosurgical training have not changed significantly over these past 50 years, the current medical educational system may promote reporting of all PPIs and in turn create the image that current physicians in training are different than their predecessors.

\section{Acknowledgments}

We would like to thank Melissa Lukehart, the program coordinator at the UPMC Department of Neurological Surgery, for her work contacting graduates and compiling the survey results. We are indebted to Dr. Peter Sheptak, who provided firsthand documentation of training events during the years from 1971 through 1974 , before the senior author joined the University of Pittsburgh.

\section{References}

1. Boockvar JA, Virella A, Kotapka M, Flamm ES, Grady MS: Neurosurgery at the University of Pennsylvania Medical Center. Neurosurgery 46:1223-1228, 2000

2. Cheesborough JE, Gray SS, Bajaj AK: Striking a better integration of work and life: challenges and solutions. Plast Reconstr Surg 139:495-500, 2017

3. Desy JR, Reed DA, Wolanskyj AP: Milestones and millennials: A perfect pairing-competency-based medical education and the learning preferences of generation Y. Mayo Clin Proc 92:243-250, 2017

4. Foreman PM, Markert JM, Diethelm AG, Hadley MN: The history of neurosurgery at the University of Alabama at Birmingham. Neurosurgery 75:483-488, 2014

5. Gelfand DV, Podnos YD, Wilson SE, Cooke J, Williams RA: Choosing general surgery: insights into career choices of current medical students. Arch Surg 137:941-947, 2002

6. Haines SJ, Rockswold GL, Maxwell RE: 75 years of neurosurgery at the University of Minnesota. Neurosurgery 74:553-560, 2014

7. House PA, Heilbrun MP, Apfelbaum RI, Kraus KL, Couldwell WT: The development of neurosurgery at the University of Utah, 1955-2009. Neurosurgery 67:781-788, 2010

8. Jain SH: Do we have a millennial physician problem? Forbes. June 11, 2016. (https://www.forbes.com/sites/ sachinjain/2016/06/11/do-we-have-a-millennial-physicianproblem/2/\#66d055d44fda) [Accessed April 24, 2018]
9. McGee JB: Teaching Millennials. Pittsburgh: University of Pittsburgh, 2011

10. McLaughlin MR, Subach BR, Lunsford LD, Jannetta PJ: The origin and evolution of the University of Pittsburgh Department of Neurological Surgery. Neurosurgery 42:893-898, 1998

11. Pingleton SK: Millennial health care: change you can believe in. Chest 142:22-29, 2012

12. Shillito J, Black PM: The Harvard Neurosurgical Service at the Children's Hospital Boston and Brigham \& Women's Hospital, 1912-2007. Neurosurgery 63:579-593, 2008

13. Silverman L: Millennial doctors may be more tech-savvy, but is that better? NPR.org. November 27, 2014. (http://www.npr. org/sections/health-shots/2014/11/27/366766639/millennialdoctors-may-be-more-tech-savvy-but-is-that-better) [Accessed April 24, 2018]

14. Unger A: Millennial physicians: how they differ from previous generations. Marketware. January 14, 2016. (http:// marketware.com/referral-development/millennial-physicians3-ways-they-differ/) [Accessed April 24, 2018]

\section{Disclosures}

Dr. Lunsford reports a consultant relationship with Insightec where he serves on the DSMB and direct stock ownership in AB Elekta.

\section{Author Contributions}

Conception and design: Lunsford. Acquisition of data: Lunsford, Newman. Analysis and interpretation of data: all authors. Drafting the article: Lunsford, Newman. Critically revising the article: Lunsford, Newman. Reviewed submitted version of manuscript: all authors. Approved the final version of the manuscript on behalf of all authors: Lunsford. Statistical analysis: Chang. Administrative/technical/material support: Lunsford. Study supervision: Lunsford.

\section{Supplemental Information \\ Previous Presentations}

Portions of this work were presented at the Society of Neurological Surgeons Meeting in Houston, Texas, May 20-23, 2016.

\section{Correspondence}

L. Dade Lunsford: University of Pittsburgh Medical Center, Pittsburgh,PA.lunsld@upmc.edu. 